\title{
Bioenergy use and food preparation practices of two communities in the Eastern Cape Province of South Africa
}

\author{
Paxie W. Chirwa \\ Department of Plant Production \& Soil Science, University of Pretoria
}

\section{Cori Ham}

Department of Forest and Wood Science, University of Stellenbosch

\author{
Stella Maphiri \\ Department of Forest and Wood Science, University of Stellenbosch
}

\author{
Marlett Balmer \\ ProBEC GTZ, Pretoria
}

\begin{abstract}
A study was undertaken in two communities that use firewood in the Keiskammahoek area of the Eastern Cape Province of South Africa to understand their behaviour with regard to energy use during food preparation as well as the extent of practising efficient cooking habits. The results showed that despite the high level of electrification, firewood was used in most households ( $\geq 60 \%$ ) for cooking while electricity was mostly used ( $\geq 90 \%)$ for lighting. Firewood is also preferred for cooking food that takes a long time to prepare, while more convenient sources of energy such as electricity is used for short periods of cooking and re-heating of food. Secondary sources of energy used for cooking included paraffin, dung, leaves and twigs. The study found that there was some deliberate use of energy saving techniques in both communities, although limited and not necessarily practiced with a view to saving energy. Less than half of the respondents soaked hard grains and beans before cooking; while all of them cut food into smaller pieces before cooking commenced. A third of respondents had utensils ready before cooking commenced in one village while two thirds placed utensils and food together before they commenced food preparations in the other village. Pots were covered with lids and water was added in small amounts as required. The heat from fire was not monitored, but fires were extinguished after use. The greatest potential for improvement exists around cooking appliances; where all households were found to be using three-
\end{abstract}

legged pots on open fires when cooking with biomass energy. Open fires are highly inefficient and the use of efficient biomass cook stoves would increase efficiency. It is recommended that in order to reduce the use of biomass-derived energy consumption and expenditure in low-income households, the use of multiple energy sources and portable energy efficient firewood stoves should be promoted. In addition, there should be an aggressive dissemination of information on further processing of fuelwood into forms that can easily be stored and used; and various forms of pre-treatment of hard foods.

Keywords: household energy, biomass energy, cooking, energy efficiency, food preparation, cooking equipment

\section{Introduction}

While there is widespread agreement that rural communities desperately need to improve their access to modern energy sources (World Bank, 2000), it has been reported that about 550 million people $(75 \%$ of the population in Sub-Saharan Africa) depend on traditional biomass (wood, charcoal, cow dung, etc.) due to lack of access to elec- 
tricity or any kind of modern energy service (Ejigu, 2008). In other parts of the Southern Africa region, firewood use in households has been estimated at 5-7 tonnes of dry wood per household per year (Grundy et al., 1993; Coote et al., 1993).

Fuelwood use has an impact on the socio-economics of a rural community as it is the main energy source in rural settings; and all cooking and most food processing depends on fuelwood. Thus, fuelwood supply can influence the amount of food prepared or cooked. Cecelski (1984) reported that in Somalia, refugees fed their bean rations to their livestock or discarded them because they could not afford the fuelwood to cook them; illustrating the fact that despite having food, without adequate cooking energy, the food was not useable since whole grains and legumes are inedible without cooking .

A very large percentage of rural households in South Africa are still dependent on firewood and paraffin for food preparation (Shackleton et al., 2007). For example, in the Limpopo and Eastern Cape Provinces, more than $50 \%$ of the households relied on firewood and paraffin for cooking (SSA, 2007). A significant number of households are expected to use firewood to some extent for decades to come, especially those marginalized either geographically or financially (Shackleton et al., 2007). Other energy sources for food preparation include paraffin, coal, liquid petroleum gas (LPG), cow dung and other biomass fuels such as crop residue. The use of more than one fuel and a range of cooking appliances is a common feature in many low income households (SPARKNET, 2004). This pattern of energy use is also referred to as multiple fuel use, meaning that households use a range of appliances and fuels interchangeably.

The implementation of appropriate kitchen management and energy savings techniques has been identified as a major contributor to energy savings, especially where these techniques are introduced in conjunction with energy efficient devices (Inter Academy Council, 2007). The objective of this study was to establish the extent to which cooks implement efficient kitchen management strategies in their daily cooking activities in rural households in two communities in the Eastern Cape Province. The Eastern Cape province of South Africa is one of the poorest provinces and more than $50 \%$ of households still rely on firewood for their energy needs (SSA, 2007).

\section{Materials and methods \\ 2.1 Study area and sample communities}

The study was conducted in the Eastern Cape Province of South Africa. The two villages selected for the survey (Cata and Tshoxa) are located in the Amahlathi Municipality (within the greater Amathole District Municipality) and are close to the town of Keiskammahoek. The Human Development Index (HDI) measured by life expectancy, literacy and income for Keiskammahoek was found to be 0.50 , which is below the average for the Eastern Cape, estimated at 0.56. It is estimated that $69.6 \%$ of the people in the Keiskammahoek area are living in poverty. Average unemployment for 2000 was estimated at $68.5 \%$, which is slightly below the estimated unemployment level of $76 \%$ for the Amahlathi Municipality in 2001. (Amahlathi IDP, 2007). Table 1 also illustrates that the $96.7 \%$ of the inhabitants of the Amahlathi Municipality earned less than R 1600 per month in 2003.The population growth rate for Keiskammahoek is estimated at $1.4 \%$ and this is likely to be representative of the situation at Cata and Tshoxa.

The Cata community (32'36'2"S; $27^{\circ} 7^{\prime} 10^{\prime \prime} \mathrm{E}$ ) is situated on the southern slopes of the Amathole Mountains, $15 \mathrm{~km}$ from Keiskammahoek in the Eastern Cape and can be classified as a rural community. There are 450 households in this village. Cata has, however, one of the highest levels of electrification in the Amahlathi Municipality with $84 \%$ of households having access to electricity (average percentage in Amahlathi Municipality is 67\%) (Amahlathi, IDP, 2007). Cata has multiple forest resources including 800 ha of indigenous forest, approximately 300 ha of pine plantations and jungle wattle areas (Ham, 2003). The Tshoxa community (32०41'25"S; 27०9"15"E) is located approximately $2 \mathrm{~km}$ from Keiskammahoek and can be classified as peri-urban. There are 600 households in this village. Unlike Cata, only $56 \%$ of households have access to electricity; and the Tshoxa village does not have any forestry activities. The area is dry and characterized by shrubs, Acacia Karoo thorn trees and some indigenous species such as sneezewood (Ptaeroxylon obliquum) and yellow wood (Podocarpus falcatus).

\subsection{Methodology}

A survey method involving interviews based on a structured questionnaire was considered the most appropriate data collection method for this project (Babbie, 2004). The unit of analysis for the questionnaire surveys was individual households (Bless \& Higson-Smith, 1995) and the target population was the 450 households at Cata and the 600 households at Tshoxa. A sample of 60 households per village was selected for the survey. The selection of an equal number of households per village makes comparisons between villages easier ( $\mathrm{Nel}$, 2008). The samples represent $13 \%$ of the households at Cata and $10 \%$ of households at Tshoxa. Households were selected based on interval or systematic sampling whereby only a certain number of houses per street were randomly selected to ensure that the survey covered the entire village (Bless \& Higson-Smith, 1995). 


\subsection{Data analysis}

The average number of people per household interviewed at both Cata and Tshoxa was four with a minimum of one at both villages and a maximum of 11 at Cata and 12 at Tshoxa. The 60 households at Cata represent 261 persons, while the 60 households at Tshoxa represent 251 persons. Results from the data analysis were presented as descriptive statistics based on the percentage of respondents (households) who replied to the individual questionnaire questions. At both villages, percentages were calculated based on a sampling population (n) of 60 households. Chi-square tests were used to compare responses of the households surveyed in the two communities using a $95 \%$ confidence interval.

\section{Results}

\subsection{Source of energy for cooking, lighting and heating}

The study showed that there was a significant difference $(p<0.001)$ in sources of energy for cooking with the majority of respondents at Cata relying on firewood $(77 \%)$ as a primary energy source for cooking, while $42 \%$ of the respondents at Tshoxa use firewood. At Tshoxa, $38 \%$ of respondents use electricity for cooking, while $18 \%$ of respondents at Cata use electricity. At Tshoxa, $17 \%$ of respondents use paraffin, while only $5 \%$ at Cata rely on paraffin for cooking energy (Table 1). Respondents also indicated that they use these primary energy sources in combination with secondary energy sources. Both at Cata (48\%) and Tshoxa (60\%), respondents indicated that they would use paraffin as a first choice, secondary energy source (in combination with, for instance, firewood and electricity). Cow dung was also listed as a second choice alternative to primary energy sources by $30 \%$ of respondents from Cata and $43 \%$ of respondents from Tshoxa.

Table 1: Primary sources of energy for cooking at Cata and Tshoxa

\begin{tabular}{lcc}
\hline Source of energy & \multicolumn{2}{c}{$\%$ of respondents } \\
& Cata & Tshoxa \\
\hline Fuelwood & $77(46)^{*}$ & $42(25)$ \\
\hline Electricity & $18(11)$ & $38(23)$ \\
\hline Paraffin & $5(3)$ & $17(10)$ \\
\hline Gas & 0 & $3(2)$ \\
\hline P-value & 0.001 & \\
\hline * Figures in brackets are the number of respondents
\end{tabular}

There was no difference in the source of lighting for the two sites, with most of the respondents at both Cata and Tshoxa using electricity for lighting $(93 \%)$ followed by paraffin $(5 \%)$ and candles $(2 \%)$, respectively. However, there was a significant difference $(p<0.04)$ in source of energy for heating between the two areas. At Cata, $78 \%$ of respondents rely on firewood, $8 \%$ on electricity and $13 \%$ on paraffin while at Tshoxa $55 \%$ rely on firewood, $10 \%$ on electricity and $32 \%$ on paraffin. Three percent of respondents at Tshoxa indicated that they do not heat their homes.

\subsection{Cooking equipment}

There were significant differences $(p<0.001)$ in the cooking equipment at the two areas when preparing food. As many as $77 \%$ of respondents at Cata use an open unshielded wood fire compared to only $42 \%$ at Tshoxa. Fireplaces consist of a flat metal base (made from for example, the lid of an oil drum or zinc roofing material) that can be moved around to cook either outside or inside the house. At Tshoxa, $40 \%$ of respondents make use of an electric stove compared to only $18 \%$ at Cata (Table 2).

There were no significant differences in the type of pots used at the two sites. All respondents who use firewood for cooking also use three-legged pots that are placed over the fires. Respondents who use gas, paraffin or electric stoves use flat bottomed aluminium pots for food preparation. Most respondents use at least two pots to prepare food. A larger pot ( 9 to13 litres) is normally used in combination with a smaller ( 3 to 6 litre) pot.

Table 2: Types of stoves and pots that respondents use for food preparation at Cata and Tshoxa

\begin{tabular}{|c|c|c|}
\hline \multirow[t]{2}{*}{ Type of stove } & \multicolumn{2}{|c|}{$\%$ of respondents } \\
\hline & Cata & Tshoxa \\
\hline Open wood & $77(46)^{*}$ & $42(25)$ \\
\hline Electric stove & $18(11)$ & $40(24)$ \\
\hline Paraffin stove & $5(3)$ & $15(9)$ \\
\hline Gas stove & 0 & $3(2)$ \\
\hline P-value & 0.001 & \\
\hline \multicolumn{3}{|l|}{ Pot type } \\
\hline Three legged pot & $77(46)$ & $42(25)$ \\
\hline Flat bottomed pot & $23(14)$ & $58(35)$ \\
\hline P-value & 0.001 & \\
\hline * Figures in brackets a & ber of $r$ & \\
\hline
\end{tabular}

\subsection{Food preparation}

There were significant differences $(p<0.0002)$ between the sites in preparation before cooking commenced in that at Cata, $65 \%$ of respondents indicated that all the food and cooking utensils are assembled compared to only $32 \%$ at Tshoxa. All respondents indicated that they cover the pot with its lid during cooking. None of the respondents monitored the heat of the fire during cooking at 
both sites but indicated that they extinguish the fire after cooking. On average, fewer respondents $(41 \%)$ indicated that they pre-soak hard grains (sorghum and maize) and beans prior to cooking. Most people $(89 \%)$ at both sites did not pound hard grains before cooking; while nearly all indicated that they cut food into smaller pieces before cooking.

Although not significant, more people at Cata $(40 \%)$ used fuelwood for warming compared to Tshoxa (20\%). On average, however, $68 \%$ of the respondents tended to favour the convenience of electricity and paraffin over firewood for the reheating of food. Additionally, respondents were asked to indicate their preferred energy source for the preparation of samp (boiled whole kernel white maize), pap (grounded maize porridge), meat, bone meat, vegetables and bread (see summary in Table 3).

There were significant differences $(p<0.01$ ) between the sites in the energy preference during the cooking of samp, bread, bones and meat (Table 3 ). More people used fuelwood (95\%) at Cata during the preparation of samp compared to Tshoxa (60\%), with some people in Tshoxa preferring to use electricity (17\%) and paraffin (13\%). A similar trend was observed in the preparation of bread, where more people at Cata $(87 \%)$ used fuelwood compared to Tshoxa (57\%); and some preferred the use of electricity (22\%) and paraffin (13\%).

For the cooking of bones, most people (90\%) at Cata used fuelwood while those at Tshoxa used a mixture of fuelwood (60) and electricity (26\%). Interestingly, during the preparation of meat, people at Tshoxa used electricity and fuelwood equally $(40 \%)$, while there was still more use of fuelwood at Cata $(68 \%)$. There were, however, no differences between the two areas in the preferred energy source for the preparation of pap and vegetables but the predominant energy sources were either fuelwood or electricity and paraffin to some extent (Table 3).

\section{Discussion}

\subsection{Sources of energy for cooking}

Cata is representative of rural villages with readily accessible firewood resources in the form of plantations, woodlots and natural forests. Tshoxa represents more urbanised villages with limited access to firewood resources. This difference was highlighted in the survey where respondents from Cata clearly prefer to use firewood for cooking while respondents from Tshoxa use a variety of energy sources for cooking. The difference in energy preference between rural and peri-urban villages has also been documented by Ham and Theron (2001); who found that in urban villages in the Eastern Cape residents use a larger variety of energy sources than in rural villages where firewood is the dominant energy source.

Although more than $80 \%$ of households at Cata have access to electricity, they prefer to use firewood as it is considered a cheaper form of energy. This mirrors the general trend in most developing countries where the introduction of electricity has not necessarily resulted in a switch from the use of fuelwood (Shackleton et al., 2007). Several studies in South Africa have shown that while South Africa consumes over $60 \%$ of the electricity on the African continent, $90 \%$ of South Africa's rural households use fuelwood energy (Shackleton et al., 2007; Davis 1998, Shackleton et al., 2004). Shackleton et al. (2007) further indicated that even with a subsidized national household electrification programme, most newly electrified households continue to use fuelwood because they cannot afford the appliances and/or the monthly costs of electricity.

While the energy policies in South Africa promote the use of renewable energy, energy strategies

Table 3: Energy source preference for the various foods at Cata and Tshoxa

\begin{tabular}{|c|c|c|c|c|c|c|c|c|c|c|c|c|}
\hline \multicolumn{5}{|c|}{ Energy source } & \multicolumn{4}{|c|}{$\%$ respondent } & \multirow{2}{*}{\multicolumn{2}{|c|}{$\mathrm{Pap}^{2}$}} & \multirow{2}{*}{\multicolumn{2}{|c|}{ Vegetables }} \\
\hline & \multicolumn{2}{|c|}{ Samp $p^{1}$} & \multicolumn{2}{|c|}{ Bread } & \multicolumn{2}{|c|}{ Bones } & \multicolumn{2}{|c|}{ Meat } & & & & \\
\hline & Cata & Tshoxa & Cata & Tshoxa & Cata & Tshoxa & Cata & Tshoxa & Cata & Tshoxa & Cata & Tshoxa \\
\hline Dung & 0 & 2 & 0 & 2 & 0 & 7 & 0 & 0 & 0 & 0 & 0 & 0 \\
\hline Electricity & 2 & 17 & 8 & 22 & 0 & 26 & 20 & 40 & 28 & 43 & 33 & 45 \\
\hline Fuelwood & 95 & 60 & 87 & 57 & 96 & 60 & 68 & 40 & 53 & 38 & 50 & 30 \\
\hline$\overline{\text { Gas }}$ & 0 & 3 & 2 & 2 & 0 & 0 & 0 & 3 & 0 & 4 & 0 & 3 \\
\hline Paraffin & 3 & 13 & 3 & 13 & 4 & 0 & 12 & 17 & 19 & 15 & 17 & 20 \\
\hline $\begin{array}{l}\text { Leaves anc } \\
\text { twigs }\end{array}$ & 0 & 5 & 0 & 4 & 0 & 7 & 0 & 0 & 0 & 0 & 0 & 2 \\
\hline $\mathrm{P}$ value & 0.0001 & & 0.01 & & 0.01 & & 0.01 & & $\mathrm{NS}^{3}$ & & NS & \\
\hline $\begin{array}{l}\text { Notes: } \\
\text { 1. Samp is } \\
\text { 2. Pap is a s } \\
\text { 3. NS denot }\end{array}$ & $\begin{array}{l}\text { mixture } \\
\text { tiff porrids } \\
\text { tes non sic }\end{array}$ & $\begin{array}{l}\text { of dried } b \\
\text { ge made } f \\
\text { gnificance }\end{array}$ & $\begin{array}{l}\text { ans and } \\
\text { om grou } \\
\text { t } p>0 \text {. }\end{array}$ & $\begin{array}{l}\text { dried who } \\
\text { nd maize } \\
05\end{array}$ & $\begin{array}{l}\text { maize } \\
\text { ur. }\end{array}$ & ernels. & & & & & & \\
\hline
\end{tabular}


based on biomass energy will have to focus on a sustainable supply of biomass as well as the optimal use of biomass energy. It is estimated that between 9 and 11 million tons of wood are used for fuel per annum, of which about 6.6 million tons are estimated to be harvested from natural woodlands (RSA, 1996). Firewood consumption per household in the Kentani area of the Eastern Cape, for instance, was estimated at $3700 \mathrm{~kg}$ per annum (Ham, 2000). The challenge for energy strategies would be to reduce the overall volume of firewood used per annum by promoting more efficient ways of using firewood and to promote the cultivation of woodlots.

\subsection{Cooking equipment and food preparation}

The general use of an open fireplace configuration is not very energy efficient and allows unrestricted airflow that can channel heat away from the pot. The inadequate availability of modern technologies for wood-based energy systems poses a major problem to the rural communities. The present inefficient use of fuelwood is not sustainable. Besides having low energy efficiency, open fire cooking places are a source of indoor air pollution (Masera et al., 2000).

Considering these factors, the need to develop technological solutions that address the problems of open fires is critical. Energy efficient stoves could play a role in improving energy transfer. Since the mid-1970s, a number of models of improved wood-burning cook stoves (ICS) have been developed that address the two main draw backs of open fires, by including a combustion chamber and a tube to take the smoke outdoors (Troncoso et al., 2007). Recent developments in stove design by Bosch, Siemens and Phillips indicate an interest in designing and producing a highly efficient stove that despite using biomass as a fuel source, can deliver clean, convenient and cheap energy for cooking in low-income households (Hegarty, 2006).

An aspect highlighted in the survey is that households would use cheaper energy sources such as firewood to cook foods that require long preparation times, while using more expensive (but more convenient) energy sources to prepare foods that require short cooking times and for re-heating food. It would seem from this study, the other forms of energy sources were easier to access compared to other developing countries. Hence, there was a limited use of other energy saving practices such as soaking or pounding grains before cooking.

When energy efficient behaviour in the two villages is examined, Cata, where $77 \%$ of the respondents use firewood, more households were found practising some form of energy efficient measures (see Table 4) than in Tshoxa. A possible explanation could be related to fuelwood collection and its associated hardship (Chirwa et al., 2008). Households, which rely on fuelwood, try to minimize usage to reduce the need for fuelwood collection. At Tshoxa, where electricity use is more prevalent, cost of electricity is the only incentive for energy saving practices.

Table 4: Use of energy efficient cooking measures

\begin{tabular}{lcc}
\hline Energy efficient practice & \multicolumn{3}{c}{ Household practising (\%) } \\
& Cata & Tshoxa \\
\hline Pre-soaking hard grains & 42 & 40 \\
\hline $\begin{array}{l}\text { Assembling cooking utensils before } \\
\text { cooking commences }\end{array}$ & 65 & 32 \\
\hline
\end{tabular}

\section{Conclusion and necommendations}

The study found that although the rural and semiurban communities in South Africa are relatively well electrified, they still use fuelwood as the main form of energy for cooking and heating; and that there is limited use of energy saving techniques in their kitchen management. The study highlighted a number of factors that can be recommended for consideration in the reduction of biomass-derived energy consumption and expenditure in lowincome households including the use of multiple energy sources which is already prevalent; and the promotion of portable energy efficient firewood stoves that would make it possible to cook inside and outside the house.

There is also a need to disseminate and/or promote information on further processing the fuelwood into forms that can easily be stored and used; (e.g. charcoal and/or briquettes) and various forms of pre-treatment of hard foods in order to improve energy efficiency in cooking procedures.

\section{Acknowledgements}

This study was funded by the SADC GTZ Programme for Biomass Energy Conservation (ProBEC) which aims to reduce biomass derived energy consumption and expenditure, particularly by low-income households. The authors acknowledge the cooperation of the Border Rural Committee, Eastern Cape office of the Department of Water Affairs and Forestry, and the communities of Cata and Tshoxa.

\section{References}

Amahlathi, I.D.P. (2007). Amahlathi Municipality Integrated Development Plan 2007/08 2011/12. Amahlathi Municipality.

Babbie, E. (2004). The Practice of Social Research. Wadsworth, Belmont, CA. 
Bless, C. \& Higson-Smith, C. (1995). Fundamentals of Social Research Methods - An African Perspective. Second edition. Juta and Co, Ltd, Cape Town.

Cecelski, E. (1984). The rural energy crisis, women's work and basic needs: Perspectives and approaches to action. ILO, Rural Employment Iblicy Research Programme, Geneva.

Chirwa, P.W. Ham, C. \& Maphiri, S. (2008). Baseline study determining consumer behaviour with regard to kitchen management and efficient cooking habits in South Africa. Report prepared for The Programme for Basic Energy and Conservation (ProBEC) by Stellenbosch University.

CIA Word Fact book, (2009). Map of South Africa [Online] Available at www.cia.gov/library/publications/the-world-factbook/print/sf.html Accessed 29 May 2009.

Coote, H.C., Luhanga, J. \& Abbot, P.G. (1993). Community use and management of indigenous forests in Malawi: the case of three villages in the Blantyre City Fuelwood Project Area. FRIM Report 93007, Forestry Research Institute of Malawi, Zomba.

Davis, M. (1998). Rural household energy consumption: The effects of access to electricity evidence from South Africa. Energy Policy 26: 207-217.

Ejigu, M. (2008). Toward Energy and livelihoods security in Africa: Smallholder production and processing of bioenergy as a strategy. Natural Resources Forum 32: 152 - 162.

Grundy, I.M., Campbell, B.M., Balebereho, S., Cunliffe, R., Tafangenyasa, C., Fergusson, R. \& Parry, D. (1993). Availability and use of trees in Mutanda Resettlement Area, Zimbabwe. Forest Ecology and Management, 56: 243-266.

Ham, C. (2000). The importance of woodlots to local communities, small scale entrepreneurs and indigenous forest conservation- A case study. Instruments for sustainable private sector forestry, South Africa series. International Institute for Environment and Development and CSIR-Environmentek, London and Pretoria.

Ham, C. \& Theron, F. (2001). Community Forestry Resources: A Case Study of Selected Woodlots in the Eastern Cape Province. Southern African Forestry Journal No. 191.

Ham, C. (2003). Facilitation and Support for the Planning and Licensing of the Chata Afforestation Project. Report prepared for the Department of Water Affairs and Forestry.

Hegarty, D. (2006). Satisfying a burning need. Phillips Research Magazine 28:28-31. Available at http://www.research.philips.com/technologies/projects/woodstove.html - Accessed 01/07/ 2009.

Inter Academy Council, (2007). Lighting the Way: Toward a sustainable energy future. http://www. interacademycouncil.net/Object.File/Master/12/ 063/2.\%20Energy\%20Demand\%20and\%20Eff iciency.pdf - Accessed 29/05/2009.

Masera, O.R., Saatkamp, B. \& Kammen, D. (2000). From Linear Fuel Switching to Multiple Cooking Strategies: A critique and Alternative to the Energy Ladder Model. In: World Development, Vol. 28, London.

Nel, D. (2008). Personal communication, July 2008. Centre for Statistical Consultation (CSC), University of Stellenbosch.

RSA, (1996). White Paper on Sustainable Forest Development in South Africa. Government Printer, Pretoria.

Shackleton, C.M., Buiten, E., Annecke, W., Banks, D.A., Bester, J., Everson, T., Fabricius, C., Ham, C., Kees, M., Modise, M., Phago, M., Prasad, G., Smit, W., Twine, W., Underwood, M., Von Maltitz, G. \& Wenzel, P. (2007). Exploring the options for fuelwood policies to support poverty alleviation policies: evolving policy dimensions in South Africa. Forests, Trees \& Livelihoods, 17: 269-292.

Shackleton, C.M., Grundy, I.M. \& Williams, A. (2004). Use of South Africa's woodlands for energy and construction. In: Lawes, M.J. Eeley, H.A. Shackleton, C.M. \& Geach, B.G. (eds). Indigenous forests and woodlands in South Africa: policy, people and practice. University of KwaZulu-Natal Press, Pietermaritzburg. pp. 337-363.

SPARKNET, (2004). South Africa Country Report Synthesis [Online] Available at http://db. sparknet.info/goto.php/SouthAfricaCountrySynt hesis - Accessed 12 August 2008.

SSA,(2007). General Household Survey 2006. Statistical Release P0318. Statistics South Africa.

Troncoso, K., Castillo, A., Masera, O. \& Merino, L. (2007). Social perceptions about a technological innovation for fuelwood cooking: Case study in Rural Mexico. Energy Policy 35, 2799 - 2810.

World Bank (2000). Energy and Development Report 2000: Energy services for the World's poor, World Bank, Washington, DC.

Received 1 July 2009; revised 31 July 2010 